Supplement of

\title{
Regional heterogeneities in the emission of airborne primary sugar com- pounds and biogenic secondary organic aerosols in the East Asian out- flow: evidence for coal combustion as a source of levoglucosan
}

Md. Mozammel Haque et al.

Correspondence to: Yanlin Zhang (dryanlinzhang@outlook.com) and Kimitaka Kawamura (kkawamura@isc.chubu.ac.jp)

The copyright of individual parts of the supplement might differ from the article licence. 

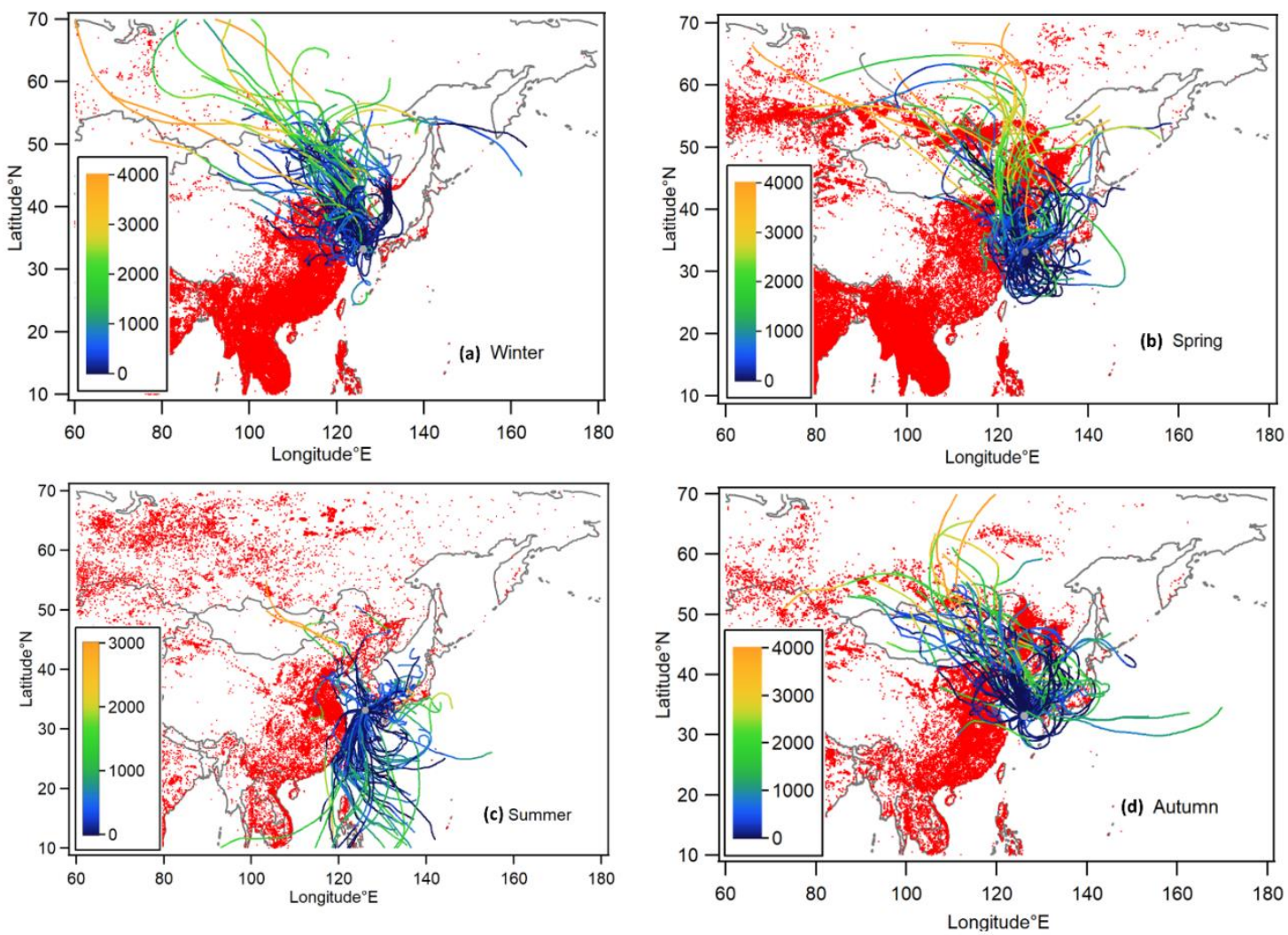


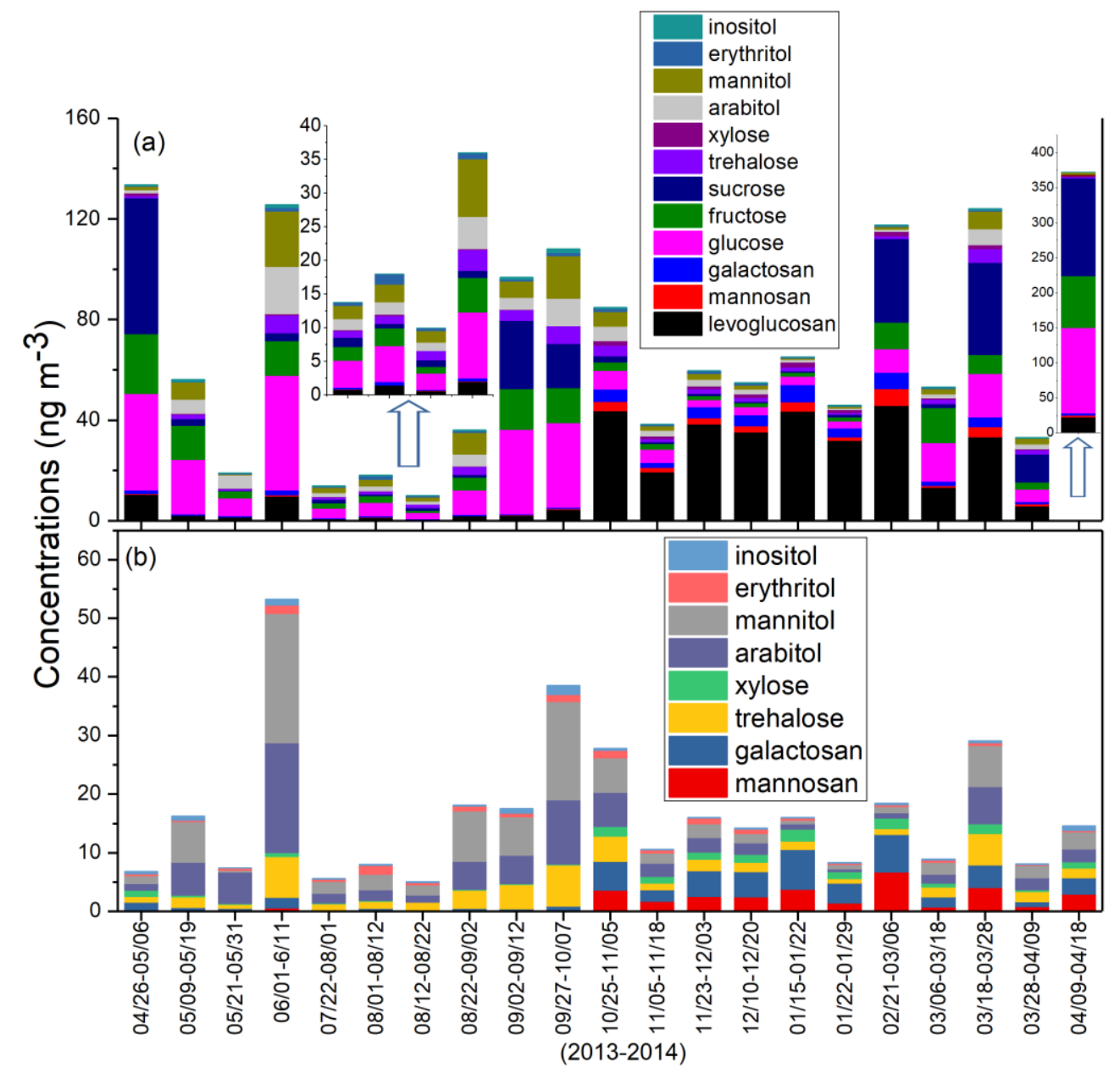

54 Figure S2. Time series of the concentrations of anhydrosugars, primary sugars, and sugar alcohols 55 during the period of study in Gosan. 


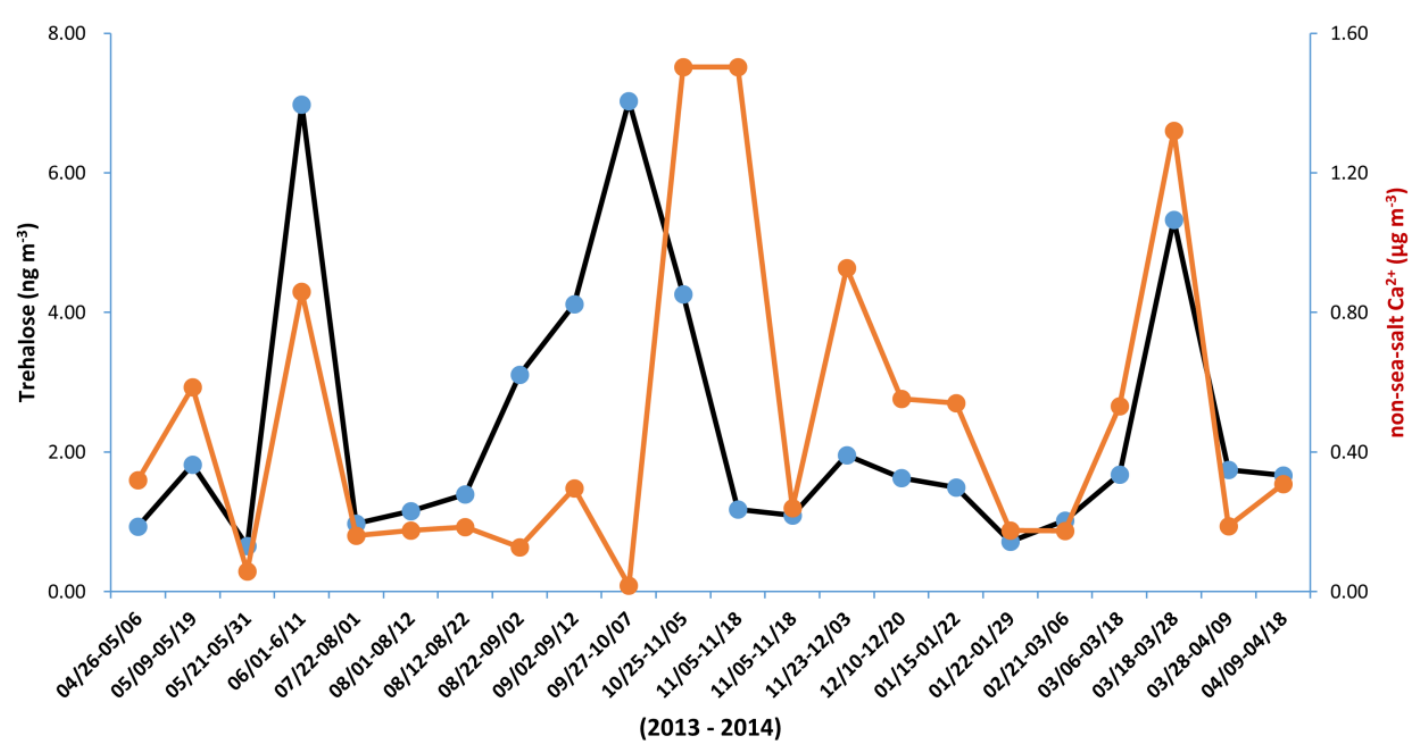

59

60 Figure S3. Temporal variability of mass concentrations of trehalose and non-sea-salt $\mathrm{Ca}^{2+}$ in TSP 61 collected over Gosan during April 203-April 2014.

62

63

64

65

66

67

68

69

70

71

72 

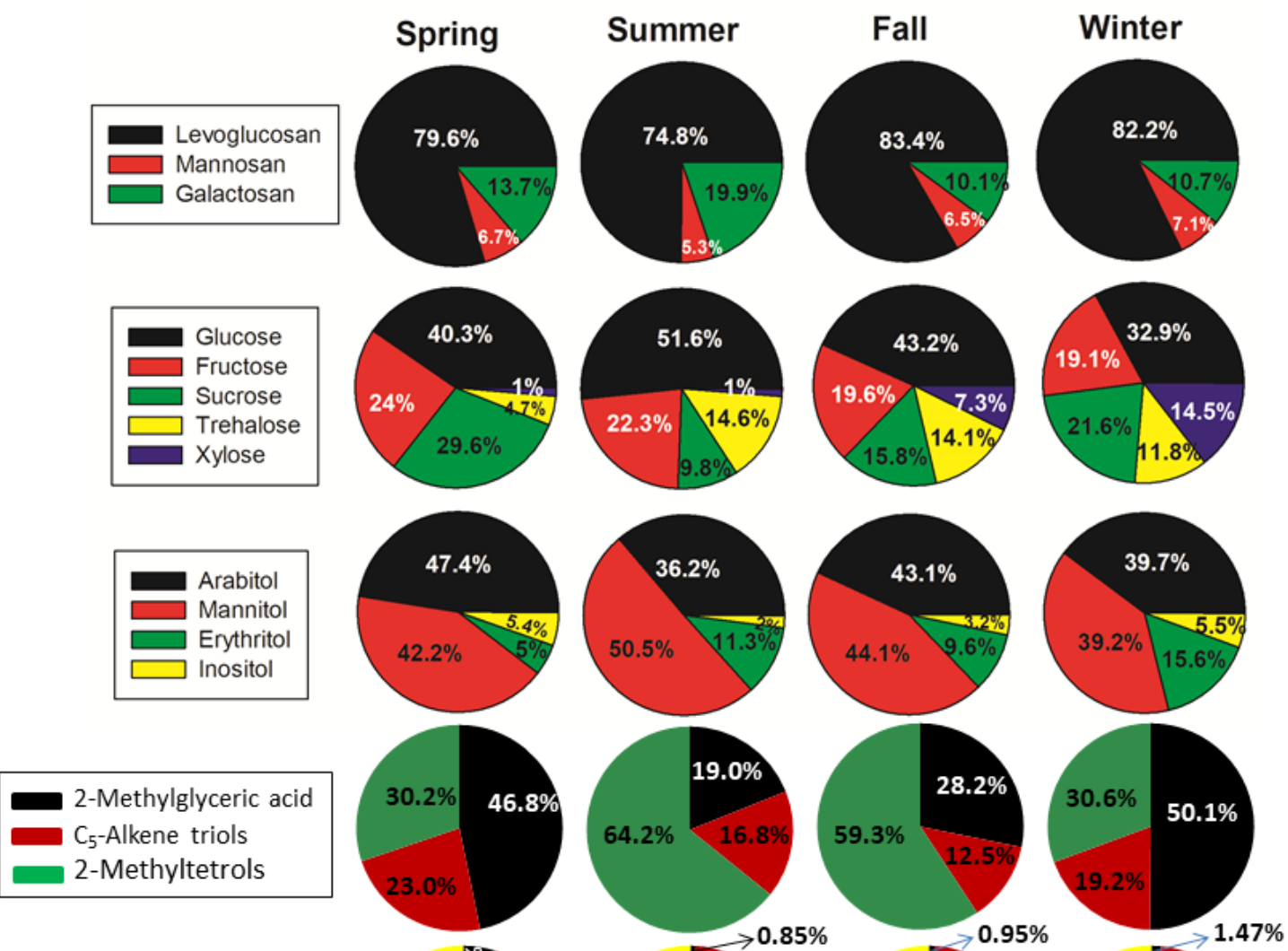

$$
\begin{aligned}
& \text { Cis-pinonic acid } \\
& \text { Pinic acid } \\
& \text { 3-HGA } \\
& \text { MBTCA }
\end{aligned}
$$
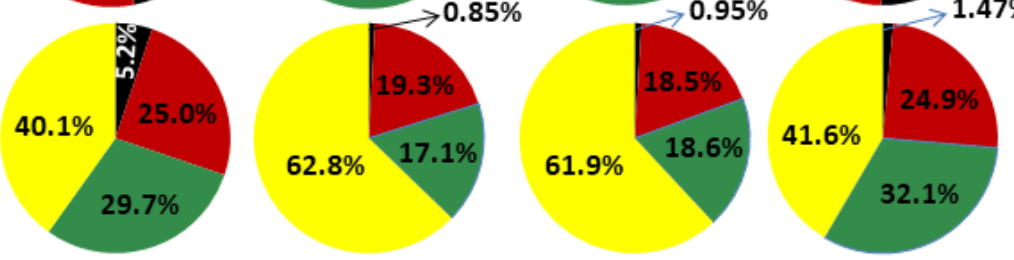

74

Figure S4. Seasonal variability of molecular distributions of anhydrosugars, primary sugars, sugar alcohols, isoprene-SOA tracers and monoterpene-SOA tracers in their total mass concentration of respective group-types in TSP samples collected over Gosan during April 2013-April 2014.

(1) 


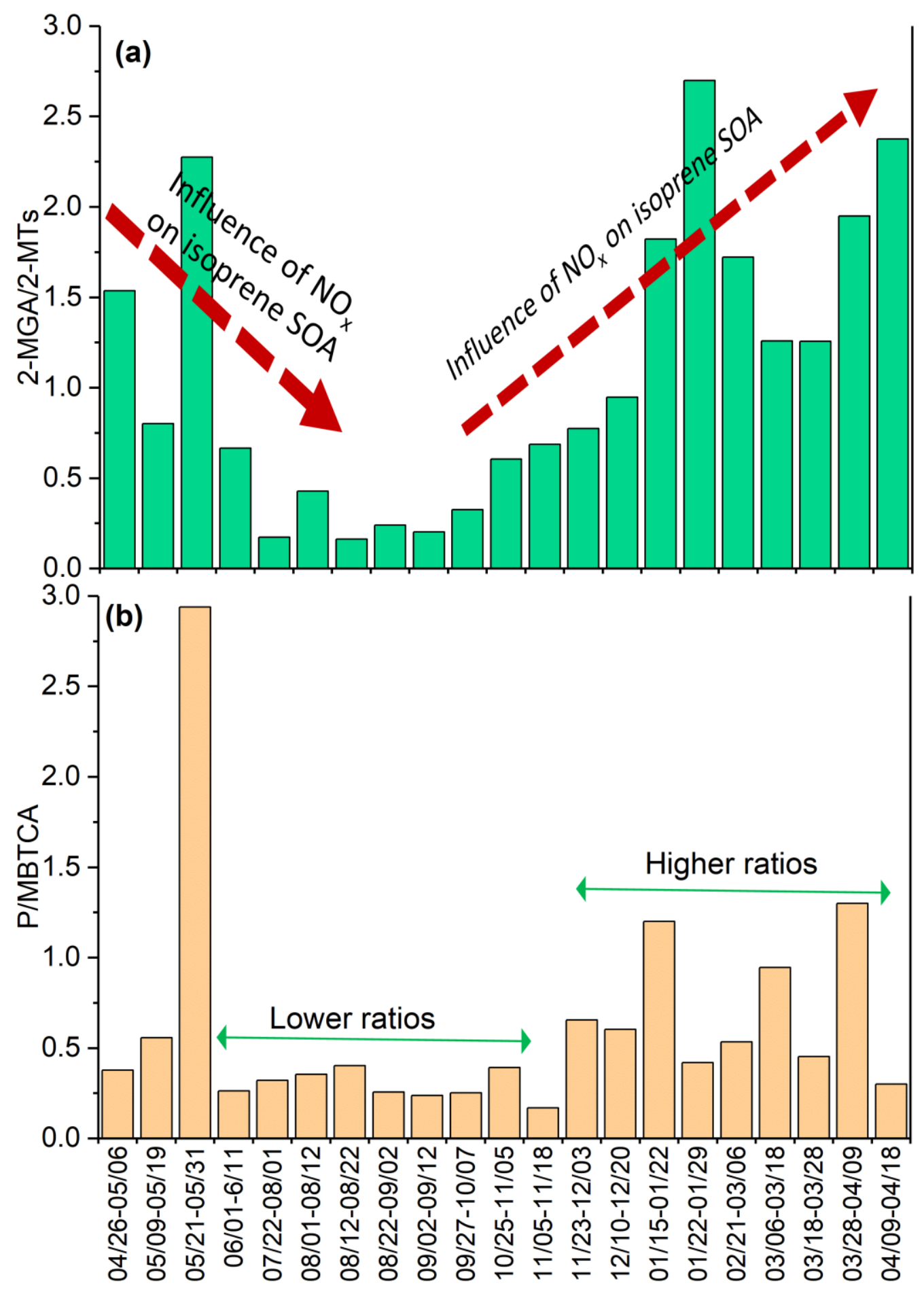

Figure S5. Diagnostic ratios of 2-methylglyceric acid/2-methyltetrols (2-MGA/2-MTs) and cispinonic acid+pinic acid/3-methyl-1,2,3-butanetricarboxylic acid (P/MBTCA) in Gosan TSP samples collected during April 2013-April 2014. 